\title{
Pattern of Crop Diversification and Disparities in Agriculture: A Case Study of Dibrugarh District, Assam (India).
}

\author{
Beejata Das ${ }^{1}$, Nitashree Mili² \\ Centre for Studies in Geography, Dibrugarh University, India.
}

\begin{abstract}
The progress of human civilization mainly depends on agriculture. In the rural areas particularly in India, for sustainable income and employment, people seems to be very much dependent on the degree of diversification of landuse towards cultivating various types of crops. Crop diversification refers to the raising of varieties of crops in a given area in a crop season. To achieve agricultural sustainability there must be crop diversification. The economy of Dibrugarh District of Assam located in the North Eastern corner of India, is mainly agrarian as most of the population are engaged in agriculture. But due to lack infrastructure and others, the agricultural sustainability in the study area is hindered. So to achieve agricultural sustainability, Dibrugarh district should go for crop diversification. In this context the present paper tries to study pattern of crop diversification and find out the nature of change in cropping pattern during the period lying between 1999-2000 and 2009-10 in Dibrugarh district. It also tries to find out the nature and magnitude of disparity in agriculture in the study area .The varying natural, socio-economic and cultural environments in Dibrugarh exercise a critical and differential effect on the adoption of modern farm technology which has resulted to disparity in agriculture.
\end{abstract}

Key words: crop diversification, cropping pattern, disparities, sustainability, dibrugarh.

\section{Introduction:}

Traditionally, Agriculture was practiced in rudimentary way that leads to degrading consequences. Now, impact of modernization brings the situation in the best practices for proper utilization, resisting soil erosion, retarding soil depletion and enhancing good production which will ultimately led to agricultural sustainability. The progress of human civilization mainly depends on agriculture. The most necessary thing in man's life is food which is derived through agriculture. The quality and the culture of the man are the dominating role in the utilization of natural resources in different environmental conditions. The present study is carried out in the dibrugarh district of Assam which consist of larger proportion of land (3381sq km) and by far the larger proportion of its population are engaged primarily in agriculture. But the district is characterized by a slow growth in agriculture because of adverse environmental consequences like flood and drought, no scope for area expansion and limited technological breakthrough. Environmental factors like terrain, rainfall and soil create disparity in agriculture in the seven circles of the district which hinders the agricultural development of the area. So, there is an urgent need for crop diversification in the study area not only to overcome the adverse environmental consequences but also to provide a boost to agricultural production.

\section{2: OBJECTIVES:}

- To study the pattern of crop diversification and find out the nature of change in cropping pattern during the period lying between 1999-2000 and 2009-10 in Dibrugarh district.

- To find out the nature and magnitude of disparity in agriculture in the study area.

\section{3: METHODOLOGY:}

The study is based on secondary data of the seven circles of Dibrugarh district collected from the office of 'Directorate of Economics and Statistics', Dibrugarh. The variation in agricultural activity can be investigated by adopting some suitable statistical techquines. To get final investigation of crop diversification, Gibb's and Martin Index of crop diversification is used. The formula read as follows:

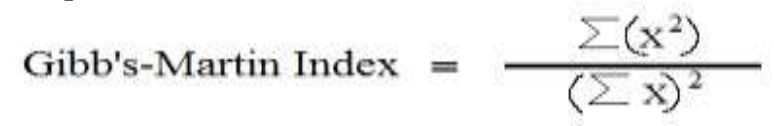

Where, $\mathrm{x}=$ percentage of total cropped area occupied by each individual crop in hectares.

The value of indices has been classified into four groups ranging from High, Medium, Low and Very Low diversified crops. 
Disparities in agriculture are analyzed by two varieties like -

a) Proportion of net area sown, and

b) Cropping intensity.

Crop Intensity (CI) is calculated by the expression

$$
\mathrm{CI}=\frac{\text { Gross cropped area }}{\text { Net area sown }}
$$

The extent of disparity is to be identified with the Co-efficient of Variation (CV).

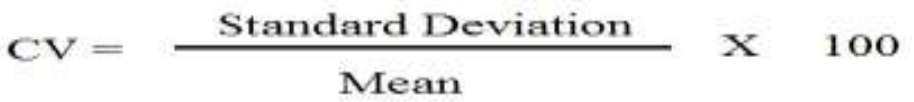

\section{4:THE STUDY AREA:}

Dibrugarh district is located between $27^{0} 53^{\prime} 8^{\prime \prime} \mathrm{N}$ to $27^{0} 42^{\prime} 30^{\prime \prime} \mathrm{N}$ latitude and $94^{0} 33^{\prime} 46^{\prime \prime} \mathrm{E}$ to $95^{0} 29^{\prime} 8^{\prime \prime} \mathrm{E}$ longitude. It is bounded by Districts of Dhemaji on the north, Tinsukia on the east, Tirap of Arunachal Pradesh on the south-east, Sivasagar on the south and Lakhimpur on the south-west (Map 1). The district covers a geographical area of $3381 \mathrm{sq}$. km.

\section{Findings:}

In the study area largest proportion of land is put to agricultural purpose. The physiography, climatic conditions and soils are very conducive for growing crops like rice, wheat, tea, maize, fruits and vegetables. Table 1 shows the percentage share of crop hectarage in seven circles of the district.

Table 1: Percentage share of crop hectarage in seven circles of Dibrugarh District (2009-10)

\begin{tabular}{|c|c|c|c|c|c|c|c|}
\hline Crops & $\begin{array}{c}\text { Dibrugarh } \\
\text { East }\end{array}$ & $\begin{array}{c}\text { Dibrugarh } \\
\text { West }\end{array}$ & Moran & Chabua & Tengakhat & Naharkatiya & Tingkhong \\
\hline Rice & 28.6 & 55.2 & 45.5 & 42.2 & 37.3 & 43 & 43.5 \\
\hline Maize & - & 0.11 & 0.02 & 0.15 & 0.03 & 0.004 & - \\
\hline Wheat & 0.12 & 0.09 & 0.05 & 0.125 & 0.09 & 0.04 & 0.0004 \\
\hline Pulses & 0.12 & 0.99 & 0.77 & 0.92 & 0.75 & 0.2 & 0.08 \\
\hline Sugarcane & 0.02 & 0.04 & 0.02 & 0.03 & 0.03 & 0.022 & 0.00008 \\
\hline Spices \& Cardamoms & 0.05 & 1.13 & 1.1 & 1.83 & 0.78 & 1.4 & 1.1 \\
\hline Fruits & 1.99 & 1.92 & 1.3 & 1.7 & 0.78 & 3.1 & 2.3 \\
\hline Vegetables & 3.6 & 5.4 & 4.14 & 3.5 & 3.7 & 4.7 & 2.6 \\
\hline Other food crops & 0.6 & 1.15 & 1.3 & 0.91 & 0.42 & 1.6 & 1.01 \\
\hline Oilseeds & 0.2 & 1.1 & 1.6 & 0.54 & 0.51 & 0.2 & 0.07 \\
\hline Tea & 62.2 & 32.1 & 43.4 & 46.7 & 54 & 44 & 48.7 \\
\hline Green manure crop & 1.46 & 0.4 & 0.12 & 1.12 & 0.11 & 1.1 & 4.4 \\
\hline Other non food crops & 0.69 & 0.74 & 0.87 & 0.4 & 0.7 & 0.84 & 4.6 \\
\hline
\end{tabular}

Source: Calculated by author.

From the table it is clear that cultivation of food grain and tea occupies the largest share of crop hectarage. In Dibrugarh the agricultural practice, is by and large, tradition-bound. The present status of farm implements, fertilizer and irrigation water used, methods of crop production and harvesting, storage adopted clearly indicate that there is yet a long way to modernize the district's farming system. This has led to degrading consequences such as reduction per capita cultivable land, low yield per capita cultivable land, erosion, soil degradation, etc. So, Dibrugarh should go for diversification of crops with views to provide a boost to agricultural production and to achieve agricultural sustainability.

\section{1:CROP DIVERSIFICATION PATTERN:}

Crop diversification refers to the raising of varieties of crops in a given area in a crop season. The more is the number of crop grown in an area, the higher is the crop diversification.

Table 3: Crop Diversification Index (Gibb's-Martin Method)

\begin{tabular}{|c|c|c|c|c|c|}
\hline Sl. no & Range of category & \multirow{2}{*}{ Category } & \multicolumn{2}{|c|}{$\begin{array}{c}\text { Crop Diversification Index } \\
\text { (Area under categories in percent) }\end{array}$} & \multirow{2}{*}{ Variation } \\
\cline { 4 - 5 } & & & $1999-2000$ & $2009-10$ & \\
\hline 1 & Above 0.65 & High & 62.9 & 16.43 & -46.5 \\
\hline 2 & $0.55-0.65$ & Medium & 37.04 & 70.84 & +33.8 \\
\hline 3 & $0.45-0.55$ & Low & 00.00 & 12.7 & +12.7 \\
\hline 4 & Below 0.45 & Very Low & 00.00 & 00.00 & 00.00 \\
\hline
\end{tabular}

Source: Calculated by author. 
The above table provides category wise explanation of changing pattern of crop diversification for the year 1999-2000 and 2009-2010 based on Gibb's and Martin Method. A perusal of Table 3 reveals that in the study area the crop diversification is not a favourable trend. The high category of crop diversification of above 65 percent occupies a large area with 62.9 percent of the total cropped area in 1999-2000 covering four circles namely Dibrugarh West, Moran, Tengakhat and Naharkatiya but in 2009-2010 there was marked decrease as the area reduced to only 16.43 percent covering only the Naharkatiya Circle. In the medium category the value of index is significantly increased by 33.8 percent in 2009-2010 covering Dibrugarh West, Chabua, Tingkhong, Moran and Tengakhat. The value of index of the lower category of 12.7 percent is also found to have increased in 2009-2010 which was nil in 1999-2000. The Very Low category of crop diversification was not recorded in both the periods.

The fall in the index value of 46.5 percent in the high category from 1999-2000 to 2009-10 is due to frequent floods; tradition bound agricultural practice and sedentary cultivation

\section{2: DISPARITIES IN AGRICULTURE IN DIBRUGARH DISTRICT:}

The varying natural, socio-economic and cultural environments in Dibrugarh exercise a critical and differential effect on the adoption of modern farm technology which has resulted to disparity in agriculture. This disparity should be reduced to the minimum to achieve overall development. Table 3 shows the extent and nature of agricultural disparities in Dibrugarh for the period 2009-10

The nature and extent of disparities in agriculture can be measured in respect of,

I. Proportion of net area sown indicating the nature of land utilization, and

II. Intensification of crops, indicating cropping pattern.

Table 4:Co-efficient Variation of Agricultural Variables

\begin{tabular}{|c|c|c|c|}
\hline Indices & Standard Deviation & Mean & Co-efficient of Variation \\
\hline Percentage of Net Area Sown & 1.67 & 14.3 & 11.68 \\
\hline Cropping Intensity & 8.81 & 132.1 & 6.67 \\
\hline
\end{tabular}

source: Calculated by author.

\section{I) Net Area Sown:}

Dibrugarh represents the tapering end of Brahmaputra valley and can be divided into three physiographic zones namely the active flood-plains and char lands, middle plains and southern foothills. The first two regions are alluvial and fertile while the third zone is composed mostly of lateritic soil. Net Sown Area is predominantly identified by various nature of land utilization depending upon the physiographic features. Therefore, the disparity is not that acute in agriculture. The co-efficient of variation of proportion of net sown area and cropping intensity have been computed which are as low as 11.68 and 6.67 respectively proves that the disparity is moderate in nature.

Table 5:Index of Net Sown Area

\begin{tabular}{|c|c|c|}
\hline Types & Percentage of Net Sown Area & Circles \\
\hline High & $>15.5$ & Tingkhong, Tengakhat \\
\hline Medium & $11.5-15.5$ & $\begin{array}{c}\text { Dibrugarh East, Dibrugarh West, } \\
\text { Moran, Naharkatiya }\end{array}$ \\
\hline Low & $<11.5$ & Chabua \\
\hline
\end{tabular}

Source: Calculated by author.

A perusal of Table 5 makes clear that large proportion of net sown area is found in Tingkhong and Tengakhat whereas low proportion is found in Chabua. Rest of the circles is situated in between these two extremes. Therefore, the inter-circle variation in respect of proportion of net sown area is more or less minimum.

\section{II) Intensification of crops:}

The cropping pattern of the district is determined by availability of technological inputs like irrigation, fertilizer input, adoption of HYV seeds, etc. Of all these inputs, irrigation forms the principal component of agricultural modernization. The study shows that the crop intensity in Dibrugarh are of three types- high, medium and low (Table 6 ) 
Table 6:Index of Crop Intensity

\begin{tabular}{|c|c|c|}
\hline Types & Percentage of Intensity & Circles \\
\hline High & $>140$ & Chabua \\
\hline Medium & $130-140$ & $\begin{array}{c}\text { Dibrugarh East, Moran, } \\
\text { Naharkatiya }\end{array}$ \\
\hline Low & $<130$ & $\begin{array}{c}\text { Dibrugarh West, Tingkhong, } \\
\text { Tengakhat }\end{array}$ \\
\hline
\end{tabular}

Source: Calculated by author.

The study reveals high intensity of cropping (>140 percent) is prevalent in Chabua which is due to the presence of alluvial soil as it provides extra physical quality. Dibrugarh East, Moran and Naharkatiya falls under moderate intensity of cropping (130-140 percent) whereas Dibrugarh West, Tengakhat and Tingkhong falls under low intensity of cropping (<130 percent). Here agriculture is mainly relied on rainfall and physical constraints. Here also the inter-circle variation is not much acute.

\section{Conclusion:}

The overall assessment shows that the crop diversification index for the year 2009-10 in comparison to 1999-2000 exhibits a decreasing trend which is not healthier for crop diversification. The environmental constraints and natural resources are localized in few areas and technological inputs, infrastructure and facilities are very low and not equally distributed in all the areas. Thus, it can be concluded that Dibrugarh should go for diversified cropping pattern to avoid adverse environmental consequences apart from reaping other benefits such as providing a boost to agricultural production, and agricultural sustainability and moreover use of modern techniques in agriculture must be increased so as to remove the disparities in agriculture.

\section{References}

[1] Ahmed Khan, Md. Zulfequar, Changing Pattern of Crop Diversification in West Bengal (1977-78 to 1988-89),1996( APH publishing corporation, pp.171-174)

[2] Das, Debashis , Disparities in Agriculture in West Bengal, 1996, (APH publishing corporation, pp. 145-146)

[3] Saharia, Umesh Chandra : Crop Diversification Pattern and Disparities In Agriculture in North-East India,1996 (Concept publishing company, pp. 163-172.)

[4] Singh, J and Dhillon, S. S. Agricultural Geography, 2006( Tata mc graw hill publishing company limited. pp. 256-264) 